\title{
Differences in Mode of Action of Cochinchinenin A and B on Tetrodotoxin-Resistant Sodium Channels
}

\author{
Chen Su ${ }^{1,2}$ Wu Shui-cai ${ }^{1}$ Zeng Yi and Liu Xiang-ming ${ }^{2^{\star}}$ \\ ${ }^{1}$ College of Life Science and Bioengineering, Beijing University of Technology, Beijing, 100124, ${ }^{1}$ College of Biomedical \\ Engineering, South-Central of University for Nationalities, Hubei, Wuhan, 430074, China.
}

*For correspondence: Email: liu.xiangming@263.net; Tel: 86-027-67843892; Fax: 86-027-67841231;

\begin{abstract}
Purpose: To explore the mechanism of antagonistic interaction between cochinchinenin $A$ and $B$ in modulating tetrodotoxin-resistant (TTR-X) sodium currents.

Methods: The time variation of the effects induced by cochinchinenin $A$ and $B$ on the TTX-R sodium currents in dorsal root ganglion (DRG) neurons of rats were observed using whole-cell patch clamp technique. Based on pharmacological fundamental theory, the modes of action of cochinchinenin $A$ and $B$ on TTX-R channels were distinguished.

Results: The scatter diagram which reflected the time variation of inhibition effect on TTX-R sodium currents induced by cochinchinenin A fitted well with occupancy theory equation (goodness of fit test, $p$ $>0.05)$, while that of cochinchinenin $B$ fitted well with rate theory equation $(p>0.05)$. The rate constants for combination and dissociation between cochinchinenin $A$ and TTX-R sodium channel were (198.7 \pm $39.9) \times 10^{-3}$ and $(41.1 \pm 6.2) \times 10^{-3}$ respectively; while corresponding values for combination and association between cochinchinenin $B$ and TTX-R sodium channel were $(99.9 \pm 16.8) \times 10^{-3}$ and $(5.3 \pm$ 0.4) $\times 10^{-3}$ respectively.

Conclusion: The main cause of the antagonistic interaction between cochinchinenin $A$ and $B$ may be attributed to the different modes of their action on TTX-R sodium channels.
\end{abstract}

Keywords: Cochinchinenin, Tetrodotoxin-resistant sodium channel, Antagonistic interaction, Occupancy theory, Rate theory

Tropical Journal of Pharmaceutical Research is indexed by Science Citation Index (SciSearch), Scopus, International Pharmaceutical Abstract, Chemical Abstracts, Embase, Index Copernicus, EBSCO, African Index Medicus, JournalSeek, Journal Citation Reports/Science Edition, Directory of Open Access Journals (DOAJ), African Journal Online, Bioline International, Open-J-Gate and Pharmacy Abstracts

\section{INTRODUCTION}

Cochinchinenin A and B are two chemical components extracted from Dragon's Blood which is a red resin from tree-stem of Dracaena cochinchinensis (Lour.) S.C. Chen. In our previous research on the analgesic mechanism of Dragon's Blood [1], both cochinchinenin A and $B$ (Fig 1) showed modulation of tetrodotoxinresistant (TTX-R) sodium currents in dorsal root ganglion (DRG) of rat neurons [2]. Moreover, the interaction of the two components was assessed to be antagonistic by the drug interaction equation of Greco et al [3, 4].

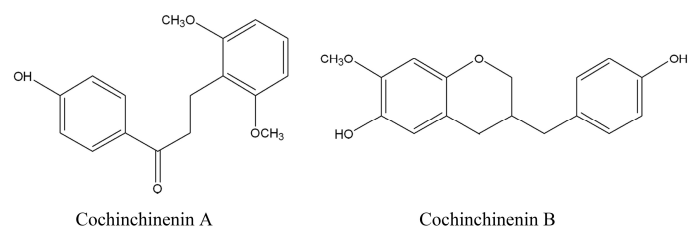

Fig 1: Chemical structures of cochinchinenin $A$ and B

Loureirin $B$ is another chemical component from Dragon's Blood known to modulate TTX-R sodium currents. Interestingly, when the 
combination of the two components modulated TTX-R sodium currents accompanied by loureirin $B$, the interaction of the combined effects was found to be synergistic [2]. To explain this phenomenon, we should first clarify the mechanism of the antagonistic interaction between cochinchinenin $A$ and $B$ because of its relatively simple process.

Rapid changes in TTX-R sodium currents have been reported in DRG neurons $8 \mathrm{~s}$ after cochinchinenin $A$ and $B$ were added [2], which indicated that the modulation by the two components on TTX-R sodium currents were produced immediately and rapidly. Thus it may be concluded that their pharmacological effects were caused by drug binding directly to a special site on sodium channel rather than acting through a second messenger-mediated signaling pathways [5]. Thus the modulation mechanism can be explained by receptor theory.

There are two different receptor models of drug behavior: one is occupancy theory proposed by Clark [6], and the other is rate theory proposed by Paton [7]. Based on the former, drug effects should gradually increase to maximal value with time, and then maintain a state of equilibrium. Based on the latter, drug effect should initially reach maximal effect, and then gradually decline to a state of equilibrium. Thus, the theory that is more suitable for describing the mode of action of a drug could be determined by detecting time variation of drug effects.

We suspect that the antagonistic interaction in the modulation on TTX-R sodium currents produced by the combination of cochinchinenin $A$ and $B$ may be related to their different modes of action on TTX-R sodium channels. Thus, the aim of this study was to observe separately the time variation of the modulation on TTX-R sodium currents by cochinchinenin $A$ and $B$ to distinguish between their modes of action on TTX-R sodium channels, and hence clarify the mechanism of their antagonistic interaction.

\section{EXPERIMENTAL}

\section{Preparation of experimental solutions and drugs}

The external solution used to record TTX-R sodium currents in DRG neurons contained (in $\mathrm{mmol} / \mathrm{L}) \quad \mathrm{NaCl}$ 125.0, Tetraethylammonium chloride (TEA-CI) 20.0, Cesium chloride ( $\mathrm{CsCl}$ ) 5.0, $\mathrm{CaCl}_{2}$ 1.8, $\mathrm{MgCl}_{2}$ 1.0, D-glucose 25.0, Hydroxyethyl piperazine ethanesulfonic acid (HEPES) 5.0 and TTX 0.001. It was adjusted to $\mathrm{pH} 7.4$ with $1 \mathrm{~mol} / \mathrm{L}$ Tetraethylammonium hydroxide (TEA-OH) and osmolarity was 313 $\mathrm{mOsmol} / \mathrm{L}$. Internal solution contained (in $\mathrm{mmol} / \mathrm{L}) \mathrm{CsCl} 70.0, \mathrm{CsF} 70.0, \mathrm{NaCl} 5.0$, EGTA 2.0, HEPES 5.0 and TTX 0.001 . It was adjusted to $\mathrm{pH} 7.4$ with $1 \mathrm{~mol} / \mathrm{L} \mathrm{CsOH}$ and osmolarity was $267 \mathrm{mOsmol} / \mathrm{L}$. TEA-Cl, CsCl, HEPES, TTX, TEA-OH, CsF, EGTA and $\mathrm{CsOH}$ were purchased from Sigma (USA). All other chemicals were of analytical grade unless otherwise stated.

Both cochinchinenin A and B were provided by Guangxi Institute of Traditional Medical and Pharmaceutical Sciences, Nanning, China. The two components were extracted and authenticated by Professor Lu Wenjie, Guangxi Institute of Traditional Medical and Pharmaceutical Sciences, Nanning, China. The purity of each component was $98 \%$. The drug solutions were prepared with the abovementioned external solution. Previous results showed that the interaction of the combined effects of $0.38 \mathrm{mmol} / \mathrm{L}$ cochinchinenin $A$ and $0.19 \mathrm{mmol} / \mathrm{L}$ cochinchinenin $B$ on TTX-R sodium currents were antagonistic [2]; hence $0.38 \mathrm{mmol} / \mathrm{L}$ cochinchinenin $A$ and $0.19 \mathrm{mmol} / \mathrm{L}$ cochinchinenin $B$, cochinchinenin $A$ at 0.19 $\mathrm{mmol} / \mathrm{L}$ and $0.76 \mathrm{mmol} / \mathrm{L}$, cochinchinenin $B$ at $0.38 \mathrm{mmol} / \mathrm{L}$ and $0.76 \mathrm{mmol} / \mathrm{L}$ were also prepared with the external solution to observe their concentration-dependent manner.

\section{Patch clamp experiments}

One month-old Wistar rats (100-150 g) provided by Laboratory Animal Center, Tongji Medical College, Huazhong University of Science and Technology (Grade SPF, SCXK (Hubei) 2010-0007) were stunned by heavy blow on the head and decapitated. DRG were taken out and placed in $4{ }^{\circ} \mathrm{C}$ saturated Dulbecco's Modified Eagle Medium (DMEM, Sigma) solution gassed with $100 \%$ oxygen. DRG neuron suspensions were obtained by using enzymatic dissociation [8]. $1 \mathrm{mg} / \mathrm{ml}$ collagenase I (Sigma) and $0.5 \mathrm{mg} / \mathrm{ml}$ trypsin (Sigma) were used to obtain DRG neuron suspensions. The solution was filtered and transferred into a $35-\mathrm{mm}$ culture dish whose bottom was previously paved with some $5 \times$ $5 \mathrm{~mm}$ microscopic glass coated with $1.0 \mathrm{mg} / \mathrm{mL}$ polylysine. After $30 \mathrm{~min}$, the solution was replaced with external solution twice. All steps were operated at $22-25{ }^{\circ} \mathrm{C}$. The animal experiments were approved by Hubei Province Association for Administration of Laboratory Animal Care in accordance with "Principles of Laboratory Animal Care" and the declaration of Helsinki [9]. 
A microscopic glass on which several DRG neurons attached was taken in a special chamber designed to perfuse external solution. Small DRG neurons (diameter approximately $10 \mu \mathrm{m}$ ) were selected for experiments as this type of cells usually expressed a high percentage of TTX-R sodium currents [10]. An EPC-9 amplifier (HEKA, Germany) was used to carry out whole-cell patch clamp experiments. After 1-5 G $\Omega$ seal formation between a pipette and DRG membrane, the membrane was ruptured and membrane capacitance was appropriately compensated. Membrane potential was clamped at $-80 \mathrm{mV}$. TTX-R sodium current was elicited by step voltage command pulse from -60 to $+60 \mathrm{mV}$ for $80 \mathrm{~ms}$ with a $10 \mathrm{mV}$ increment. The sodium current which was still present at the end of a $5 \mathrm{~ms}$ depolarizing pulse to $0 \mathrm{mV}$ [11] can be identified as TTX-R sodium current. After control currents were recorded, the drug solution was delivered to the cell over $8 \mathrm{~s}$ by using a rapid solution exchange system (DAD-12, ALA, USA), and then the currents were recorded once every 10s. The records which continued at least for 2 min were regarded as effective records. Before the operation on the next neuron, the residual drug was washed out by 1 min perfusion with external solution.

\section{Differentiation of mode of action of drug on TTX-R sodium channel}

Based on receptor theory, in the system of one kind of drug and one type of receptor, a statement of the interaction between the drug and the receptor follows the reaction in Eq 1 [12].

$$
\begin{aligned}
& k_{1} \\
L+(1-B) & \Leftrightarrow B \\
& k_{2}
\end{aligned}
$$

where $L$ is the drug dose, the total dose of the receptor is set at 1 , among which the proportion of the receptor occupied by the drug is denoted by $B . k_{1}$ and $k_{2}$ are the rate constants for combination and dissociation, respectively.

Before equilibrium, the reaction rate equals the differential value between the rate of combination and that of dissociation, solving the differential equation, as in Eq 2.

$$
B=\frac{L}{L+\frac{k_{2}}{k_{1}}}\left[1-e^{-\left(k_{1} L+k_{2}\right) t}\right]
$$

If the mode of action of drug on the receptor complies with occupancy theory, the effect intensity produced by drug combining with their receptor depends on the proportion of the receptor occupied by the drug, namely $B$. In this work, the drug effect was described by the percentage inhibition rate of the drug on peak value of TTX-R sodium current, namely $E_{t}$. Accordingly, $E_{t}$ at the time point $t$ is as in Eq 3.

$$
E_{t}=B=\frac{L}{L+\frac{k_{2}}{k_{1}}}\left[1-e^{-\left(k_{1} L+k_{2}\right) t}\right]
$$

where $L$ is the drug concentration, $t$ is the time point after the administration of drug, $k_{1}$ and $k_{2}$ are the same with those in the Eq 2. If the mode of action of drug on the receptor complies with rate theory, before equilibrium, the positive reaction rate equals the rate of combination, as indicated in Eq 4 [13].

$$
V_{\text {combination }}=k_{1} L(1-B)
$$

Here the interaction between the drug and the receptor still follows the Eq 1 and the effect intensity produced by drug depends on the rate of drug-receptor interaction, namely $V_{\text {combination }}$. Accordingly, the drug effect $E_{t}$ at the time point $t$ could be calculated by substitution of Eq 2 into Eq 4 to give Eq 5 .

$$
E_{t}=V_{\text {combination }}=\frac{L}{L+\frac{k_{2}}{k_{1}}}\left[k_{2}+k_{1} L e^{-\left(k_{1} L+k_{2}\right) t}\right] \cdots \cdots \text { (5) }
$$

where $E_{t}, L, t, k_{1}$ and $k_{2}$ respectively are the same with those in Eq 3.

\section{Statistical analysis}

Using Pulse Fit software (version 8.5, HEKA, Germany) and Igor Pro software (version 4.09, WaveMetrics, USA), patch clamp experimental data were analyzed. The peak value of TTX-R sodium current measured in control was denoted as $I_{\text {control }}$. Considering that the drug was delivered to the cell over $8 \mathrm{~s}$ and then TTX-R sodium current was recorded about $2 \mathrm{~s}$, the first peak value of TTX-R sodium current in the presence of drug was denoted as $I_{10 s}$ and the corresponding time point after the administration of drug was denoted as $10 \mathrm{~s}$. Subsequently the peak values of TTX-R sodium currents recorded once every $10 \mathrm{~s}$ in turn were denoted as $I_{20 s}, I_{30 s}$, etc. Normalized peak value of TTX-R sodium current was calculated as the peak value of TTX-R sodium current recorded at each time point divided by the one 
in control ( $\left.I_{\text {control }}\right)$. Normalized value of $I_{\text {control }}$ was 1.0.

Percent inhibition rate on peak value of TTX-R sodium current produced by drug was calculated using Eq 6.

$E=$ Inhibition $\%=\frac{I_{\text {control }}-I_{\text {drug }}}{I_{\text {control }}} \times 100 \%$

where $I_{\text {control }}$ and $I_{\text {drug }}$ are the peak values of TTX-R sodium currents in control and in the presence of drug respectively.

Data were expressed as the mean \pm SEM. Student $t$-test was used to determine whether the means of two groups were statistically different from each other. Analysis of variance (ANOVA) was used to determine whether differences existed among more than two groups. The goodness of the curve fitting was tested by Chi-square test. By convention, $p$ values < 0.05 were considered statistically significant.

\section{RESULTS}

\section{"Run-down" of TTX-R sodium currents}

When the drug effects on voltage-gated ion currents were observed by whole-cell patch clamp technique, various command voltage stimuli and drugs were usually applied on the cell surface which sealed and influenced both channel protein and its seal formation. As the influencing degree could be cumulated along with the time, the ion currents activated by command voltage stimuli could not keep stable and gradually attenuate [14]. Consequently, in the long-term, whole-cell patch clamp recordings, the rule of attenuation of TTX-R sodium currents should be considered.

Experiments were performed on 6 neurons. A 52-fold increase of TTX-R sodium currents for 9 minutes were elicited in each neuron. The $1-t$ curve of TTX-R sodium current was drawn to reflect its attenuation rule (Fig.2).

There were significant differences $(p<0.05)$ in the peak values of TTX-R sodium currents recorded at various time points, which indicated that run-down does exist in long-term TTX-R sodium current recordings. However, the run-down usually occurred in $5 \mathrm{~min}$ after obtaining whole-cell access and subsequently the peak values of TTX-R sodium currents tended towards stabilization. There were no differences in the peak values of TTX-R sodium currents from $31^{\text {st }}$ recording to $52^{\text {nd }}$ recording. Therefore, long-term TTX-R current recordings should be carried out until $5 \mathrm{~min}$ after the successful seal formation and the time for observation should less than $3 \mathrm{~min}$.

\section{Determination of mode of action of cochinchinenin A on TTX-R sodium channel}

From 10 s to 130 s after the administration of drug, cochinchinenin $A$ at 3 concentrations all produced various inhibition rates on the peak values of TTX-R sodium currents at 13 time points ( $t$-test, $p<0.05)$. However, there were significant differences (ANOVA, influencing factor is time, $p<0.05$ ) in the inhibition rates induced by $0.19 \mathrm{mmol} / \mathrm{L}$ cochinchinenin $A$ on TTX-R sodium currents at various time points after the administration of drug. Similarly, there were differences $(p<0.05)$ in those induced by $0.38 \mathrm{mmol} / \mathrm{L}$ cochinchinenin $A$ and there were differences $(p<0.05)$ in those induced by 0.76 $\mathrm{mmol} / \mathrm{L}$ cochinchinenin $A$. The scatter diagram which reflected the time variation of inhibition effect induced by cochinchinenin $A$ was drawn and the part showing an upward trend was fitted with the equation (3) (Fig.3) to determine which theory was complied by the mode of action of cochinchinenin A on TTX-R sodium channel.

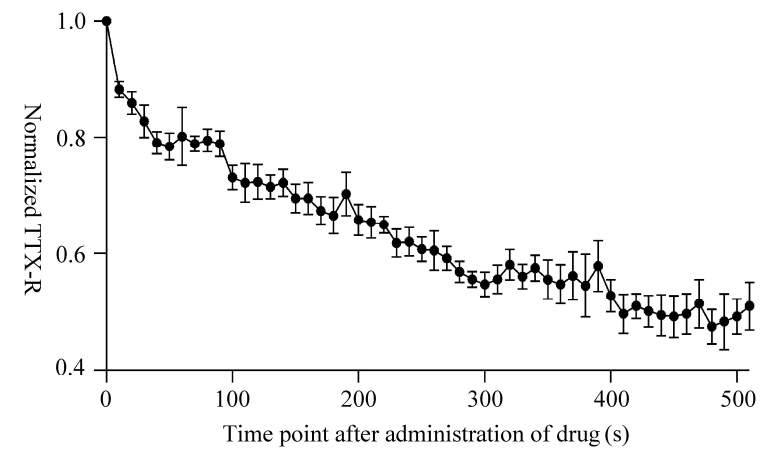

Fig 2: $l-t$ curve of TTX-R sodium current

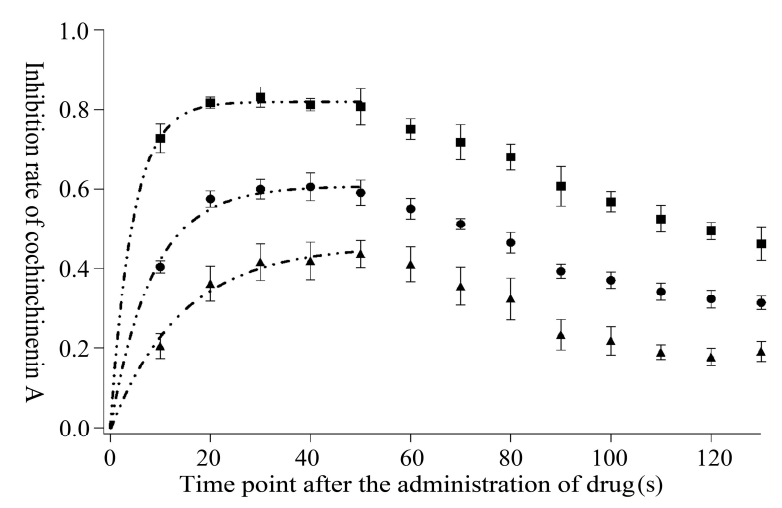

Fig 3: Time-response curves of cochinchinenin A at 3 concentrations

$\Delta=0.19 \mathrm{mmol} / \mathrm{L}$ cochinchinenin $\mathrm{A} ; \bullet=0.38 \mathrm{mmol} / \mathrm{L}$ cochinchinenin $A$; $\boldsymbol{\square}=0.76 \mathrm{mmol} / \mathrm{L}$ cochinchinenin $A$; = fitting curve. 
Table 1: Time-response curve-fitting results of cochinchinenin $A$ at 3 concentrations

\begin{tabular}{ccccccc}
\hline $\begin{array}{c}\text { Cochinchinenin } \\
\text { A concentration } \\
\text { (mmol/L) }\end{array}$ & \multicolumn{2}{c}{$\begin{array}{c}\text { 95\% confidence intervals of the } \\
\text { parameters in Eq 3 }\end{array}$} & \multicolumn{2}{c}{$\begin{array}{c}\text { Goodness of } \\
\text { fit test }\end{array}$} & \multicolumn{2}{c}{ Values of parameters } \\
\hline 0.19 & $k_{1}$ & $k_{2}$ & $\mathrm{X}^{2}$ & $P$ & $k_{1}$ & $k_{2}$ \\
0.38 & {$[0.1294,0.2058]$} & {$[0.0252,0.0479]$} & 0.00124 & 0.05 & & \\
0.76 & {$[0.1376,0.2416]$} & {$[0.0339,0.0558]$} & 0.00124 & 0.05 & $0.1987 \pm 0.0399$ & $0.0411 \pm 0.0062$ \\
\hline
\end{tabular}

Table 2: Time-response curve-fitting results of cochinchinenin $B$ at 3 concentrations

\begin{tabular}{ccccccc}
\hline $\begin{array}{c}\text { Cochinchinenin B } \\
\text { concentration } \\
\text { (mmol/L) }\end{array}$ & \multicolumn{2}{c}{$\begin{array}{c}95 \% \text { confidence intervals of the } \\
\text { parameters in Eq 5 }\end{array}$} & \multicolumn{2}{c}{$\begin{array}{c}\text { Goodness of fit } \\
\text { test }\end{array}$} & \multicolumn{2}{c}{$\begin{array}{c}\text { Values of } \\
\text { parameters }\end{array}$} \\
\hline 0.19 & $k_{1}$ & $k_{2}$ & $\mathrm{X}^{2}$ & $P$ & $k_{1}$ & $k_{2}$ \\
\hline 0.38 & {$[0.0721,0.1331]$} & {$[0.0045,0.0062]$} & 0.00018 & 0.05 & $0.0999 \pm$ & $0.0053 \pm$ \\
0.76 & {$[0.0691,0.1295]$} & {$[0.0041,0.0061]$} & 0.00039 & 0.05 & 0.0168 & 0.0004 \\
\hline
\end{tabular}

The corresponding curve-fitting results are shown in Table.1. It can be seen that the mode of action of cochinchinenin A on TTX-R sodium channels complied with occupancy theory. Through the time-response curve-fitting of cochinchinenin A at 3 concentrations, 3 groups of fitted values of $k_{1}$ and $k_{2}$ could be obtained. There was no difference between them, which indicates that the rate constants for combination and dissociation between cochinchinenin $A$ and TTX-R sodium channels are their natural characteristics and are independent of drug concentration.

\section{Discrimination of action mode of cochin- chinenin $B$ on TTX-R sodium channel}

From 10 to $60 \mathrm{~s}$ after the administration of drug, $0.19 \mathrm{mmol} / \mathrm{L}$ cochinchinenin $B$ produced various significant inhibition rates on the peak values of TTX-R sodium currents at 6 time points $(p<0.05)$ and there were differences (one-way ANOVA, influencing factor is time, $p$ $<0.05)$ in them. From 10 to $50 \mathrm{~s}$ after the administration of drug, $0.38 \mathrm{mmol} / \mathrm{L}$ cochinchinenin $B$ produced various significant inhibition rates $(p<0.05)$ and there were differences $(p<0.05)$ in them. From 10 to $40 \mathrm{~s}$ after the administration of drug, significant inhibition rates were also produced by 0.76 $\mathrm{mmol} / \mathrm{L}$ cochinchinenin B $(p<0.05)$. The same curve fitting method for cochinchinenin $A$ was used and the scatter diagram was drawn. The part showing a downward trend fitted with Eq 5 (Fig 4) to determine which theory was conformed to by the mode of action of cochinchinenin B on TTX-R sodium channel.

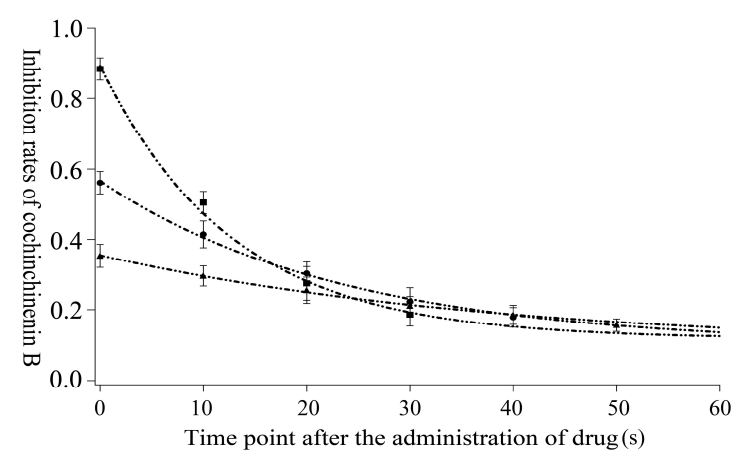

Fig 4: Time-response curve-fitting of cochinchinenin $B$ at 3 concentrations

$\Delta=0.19 \mathrm{mmol} / \mathrm{L}$ cochinchinenin $\mathrm{B} ; \bullet=0.38 \mathrm{mmol} / \mathrm{L}$ cochinchinenin $\mathrm{B} ; \boldsymbol{-}=0.76 \mathrm{mmol} / \mathrm{L}$ cochinchinenin $\mathrm{B}$; = fitting curve.

The corresponding curve-fitting results are shown in Table.2. It can be seen that the mode of action of cochinchinenin B on TTX-R sodium channels complied with rate theory. Similarly, there was no differences in the 3 groups of fitted values of $k_{1}$ and $k_{2}$ obtained, which indicated that the rate constants for combination and dissociation between cochinchinenin $\mathrm{B}$ and TTX-R sodium channel are their natural characteristics and are independent of drug concentration.

\section{DISCUSSION}

The mode of action of cochinchinenin A on TTX$\mathrm{R}$ sodium channels complied with occupancy theory. The inhibition intensity produced by cochinchinenin A on TTX-R sodium currents depends on the proportion of the TTX-R sodium channel occupied by it. It could be calculated that the rate constant for combination of cochinchinenin A and TTX-R sodium channel was 5 times higher than that for dissociation. 
Thus at the beginning of the reaction, the drugs rapidly combined with their receptors to form the resulting drug-receptor complex, and that the proportion of the number of complexes formed increased continuously until the maximum was reached.

Similarly, the mode of action of cochinchinenin B on TTX-R sodium channels complied with rate theory. The inhibition intensity produced by cochinchinenin B on TTX-R sodium currents depends on the rate of the TTX-R sodium channel occupied by it. It could be calculated that the rate constant for combination of cochinchinenin B and TTX-R sodium channel was 20 times higher than that for dissociation. Thus at the beginning of the reaction, there was a quite high rate of the drugs combining with their receptors to produce a great inhibition on TTX-R sodium currents. The number of the receptors unoccupied subsequently became less and less, meanwhile, the drug-receptor complexes formed did not really dissociate, which was accompanied with a characteristically decreasing inhibition on TTX-R sodium currents.

In a previous research [2], the dose-response curve of cochinchinenin $A$ showed that its maximum inhibition rate on TTX- $R$ sodium currents could reach $100 \%$, namely 1 . This is also true in cochinchinenin $B$, which suggested that cochinchinenin $A$ and cochinchinenin $B$ are equal in the intrinsic activity. The results of this research show that cochinchinenin $A$ and $B$ are different in their rate constants for combining with TTX-R sodium channel. It is only in competitive antagonism between two kinds of drugs and one type of receptor [12] that these two conditions can appear simultaneously. Thus, it can be speculated that cochinchinenin $A$ and $B$ competitively combine at the same site of TTX-R sodium channel.

As the rate constant of combination of cochinchinenin A and TTX-R sodium channel was twice that of cochinchinenin $B$, when cochinchinenin A and B competitively combined at the same site of TTX-R sodium channel, the rate at which cochinchinenin $B$ combines with TTX-R sodium channel should decreased, causing lower inhibition rate induced by cochinchinenin B on TTX-R sodium currents compared with that induced by cochinchinenin B alone. Similarly, as the rate constant of dissociation of cochinchinenin $B$ and TTX- $R$ sodium channel was one-eighth of that of cochinchinenin $A$, even if this occurred in the later reaction phase, the TTX-R sodium channels occupied by cochinchinenin B did not easily dissociate and recombine with cochinchinenin $A$, which also caused the lower inhibition rate induced by cochinchinenin A on TTX-R sodium currents compared with that induced by cochinchinenin A alone.

Since Paton proposed the rate theory in 1961 , it has taken a long time for mankind to regard the theory only as a conceptual challenge to occupancy theory. Based on our current understanding of receptor systems, rate theory with limited applicability does not appear to explain well-characterized receptor-dependent phenomena. However, cochinchinenin B, a component extracted from tropical traditional medicine, Dragon's Blood, not only acted as antagonist of TTX-R sodium channel, but also interacted with TTX-R sodium channel obeying the principle of rate theory, which showed the diversity and pleiotropy of tropical traditional medicine. According to the rate theory, some agents with very small rate constant of dissociation can be regarded as an antagonist.

TTX-R sodium channel is selectively expressed by putative nociceptors, is a common target for a number of hyperalgesic agents, and is selectively modulated by these agents in a manner consistent with nociceptor sensitization. Pharmacological therapies designed to specifically block TTX-R sodium channel might be a potential treatment for pain syndromes characterized by nociceptor sensitization [15]. The explanation for the mechanism of the antagonistic interaction between cochinchinenin $A$ and $B$ will contribute to research on the optimum compatibility proportion of the components extracted from Dragon's Blood that would modulate TTX-R sodium channel.

\section{CONCLUSION}

The mode of action of cochinchinenin A on TTX$R$ sodium channel complied with occupancy theory while that of cochinchinenin B complied with rate theory. The different modes of action on TTX-R sodium channel, different rate constants of combination and different rate constants of dissociation directly induce the antagonistic interaction between cochinchinenin A and B.

\section{ACKNOWLEDGEMENT}

This work was supported by National Natural Science Foundation of China (Grant 30973961); Young Chenguang Foundation of Wuhan (Grant 201150431075); and Academic Team of South Central University for Nationalities (Grant XTZ09010). In particular, The authors thank Professor Lu Wenjie for 
providing cochinchinenin $A$ and $B$ used in the work.

\section{REFERENCES}

1. Lu WJ, Wang XF, Chen JY, Lv Y, Wu N, Kang WJ, Zheng QT. Studies on chemical constituents distilled from Dracaena cochinchinensis with chloroform. Yao Xue Xue Bao 1998; 33: 755-758.

2. Liu XM, Chen S, Zhang $Y X$, Zhang F. Modulation of Dragon's Blood on tetrodotoxin-resistant sodium currents in dorsal root ganglion neurons and identification of its material basis for efficacy. $\mathrm{Sci}$ China Ser C 2006; 49(3): 274-285.

3. Greco WR, Park HS, Rustum YM. Application of a new approach for the quantitation of drug synergism to the combination of cis-diamminedichloroplatinum and $1-\beta-D$-arabinofuranosylcytosine. Cancer Res 1990; 50: 5318-5327.

4. Snyder S, D'Argenio DZ, Weislow O, Bilello JA, Drusano $G L$. The triple combination indinavir-zidovudinelamivudine is highly synergistic. Antimicrob Agents Ch 2000; 44: 1051-1058.

5. Taupenot L, Mahata M, Mahata SK, O'Connor DT. Timedependent effects of the neuropeptide PACAP on catecholamine secretion. Hypertension 1999; 34: $1152-1162$.

6. Yamada $Y$, Sugiura M, Higo K, Ozeki T, Takayanagi $R$, Okuyama K, Yamamoto K, Satoh H, Sawada Y, Iga $T$,. Receptor occupancy theory-based analysis of antiemetic effects and standard doses of 5-HT3 receptor antagonists in cancer patients. Cancer Chemother Pharmacol 2004; 54: 185-190.
7. Paton WDM. A theory of drug action based on the rate of drug-receptor combination. Proceedings $B$ : Biological Sciences 1961; 154: 21-69.

8. Liu XM, Chen S, Yin SJ, Mei ZN. Effects of Dragon's Blood and its component loureirin $B$ on tetrodotoxinsensitive voltage-gated sodium currents in rat dorsal root ganglion neurons. Sci China Ser $C$ 2004; 47: 340-348.

9. World Medical Organization. Declaration of Helsinki. Brit Med J 1996; 313(7070): 1448-1449.

10. Tate $S$, Benn $S$, Hick $C$, Trezise D, John V, Mannion RJ, Costigan M, Plumpton C, Grose D, Gladwell Z, et al. Two sodium channels contribute to the TTX-R sodium current in primary sensory neurons. Nat Neurosci 1998; 1: 1653-1655.

11. Song JH, Huang CS, Nagata K, Yeh JZ, Narahashi T. Differential action of riluzole on tetrodotoxinsensitive and tetrodotoxin-resistant sodium channels. Pharmacol 1997; 282: 707-714.

12. Zhou TC. Receptor biochemical pharmacology. 1th ed. Beijing: People's Health Publishing House; 1985. $213 p$.

13. Limbird LE. Cell surface receptors: a short course on theory and methods. 3rd edn. New York: Springer; 2004. 219p.

14. Alford S, Frenguelli BG, Schofield JG, Collingridge GL. Characterization of $\mathrm{Ca}^{2+}$ signals induced in hippocampal CA1 neurones by the synaptic activation of NMDA receptors. J Physiol 1993; 469: 693-716.

15. Gold MS, Reichling DB, Shuster MJ, Levine JD. Hyperalgesic agents increase a tetrodotoxinresistant $\mathrm{Na}^{+}$current in nociceptors. Proc Natl Acad Sci USA 1996; 93: 1108-1112. 